\title{
DETECTION OF ANTIBIOTIC SENSITIVITY PROFILE OF CHRONIC MASTITIS USING BENTONITE CLAY AS SUBSTRATE
}

\author{
R. MISHRA*, K. K. SARDAR ${ }^{1}$, P. K. RATH ${ }^{2}$, B. P. MISHRA ${ }^{3}$, \\ K. SINGH BISHT AND I. ANAND SENAPATI \\ Department of Veterinary Microbiology \\ College of Veterinary Science and Animal Husbandry \\ OUAT, Bhubaneswar-751 003, Odisha, India
}

\begin{abstract}
This study is conducted to examine the change in pattern of the antibiotic sensitivity profile of Staphylococcus aureus, Escherichia coli and Pseudomonas aeruginosa isolated from the recurrent bovine mastitis cases. A total of 75 mastitis milk samples were screened for the presence of $S$. aureus $(\mathrm{n}=52)$, E. coli $(\mathrm{n}=37)$ and Pseudomonas aeruginosa $(\mathrm{n}=19)$ isolates. All the isolated bacteria were then subjected to antibiotic sensitivity test using nine specific commonly used antibiotics. Mueller Hinton Agar (MHA) along with $0.5 \%$ Bentonite clay was used as a substrate for biofilm producing bacterial isolates. The test results revealed that the resistance against antibiotics is comparatively more pronounced in biofilm forming isolates than their planktonic counterparts. In order to nullify any error possibility in biofilm growth and to establish an ideal substrate, there is need for more intensive studies using different substrate for modified ABST.
\end{abstract}

Key words: Antibiotic resistance, Antibiotic sensitivity test, Bentonite, Biofilm, Bovine mastitis

Mastitis is the most prevalent disease of dairy cattle affecting production and physical traits, which is caused by multi-etiological agents. Bovine mastitis is considered as the economically most important disease of dairy cattle, due to huge losses incurred by dairy sector annually (Heikkilä A-M et al.,
2018). The predominant etiologic agents are Staphylococcus aureus, Streptococcus sp., E. coli, Pseudomonas aeruginosa and other pathogens. So, now-a-days large emphasis is put on the definitive diagnosis of causal pathogen and its antimicrobial sensitivity pattern. It will help in selective treatment

\footnotetext{
*Corresponding Author

${ }^{1}$ Department of Veterinary Pharmacology and Toxicology, College of Veterinary Science and Animal Husbandry, OUAT, Bhubaneswar, Odisha-751003, India

${ }^{2}$ Department of Veterinary Pathology, College of Veterinary Science and Animal Husbandry, OUAT, Bhubaneswar, Odisha-751003, India

${ }^{3}$ Department of Livestock Products Technology, College of Veterinary Science and Animal Husbandry, OUAT, Bhubaneswar, Odisha-751003, India
} 
against etiological agent(s) of mastitis and reduces resistance and indiscriminate use of antimicrobial agents. But still sometimes the cure rate is disappointing which results in recurrent infection. These chronic recurrent infections are due to the ability of bacteria to remain protective as aggregative form inside an extra polymeric matrix called as biofilm (Homoe et al., 2009; KirketerpMøller et al., 2010). Melchoir et al. (2006) has reported that on comparative analysis of biofilm forming bacterial agent and its sessile counterpart showed a marked difference in sensitivity pattern, when screened by disk diffusion tests. In the present study, a modified media is used to compare the sensitivity patterns of both biofilm forming and non-biofilm forming microbial isolates obtained from Chronic Bovine Mastitis.

\section{MATERIALS AND METHODS}

In the present study, 75 number of milk samples were collected from chronic bovine mastitis cases. All the animals were presented to Teaching Veterinary Clinical Complex (TVCC) of Odisha Veterinary College for treatment. It has been revealed by the owner that the cows have earlier history of mastitis and had undergone treatment for 2 to 3 times in the local veterinary dispensary. As TVCC is referral hospital of the state, the cows mostly with recurrent mastitis, after earlier treatment, were presented for further treatment. The isolation and identification of the isolates were done according to the method of Cruickshank et al. (1980). Then all isolates were screened for their biofilm producing ability by using Congo Red Agar method (Cruzado-Bravo et al., 2019) and by Tube method (Dheepa et al., 2011). ABST for the biofilm forming bacterial isolates selected randomly for Staphylococcus aureus $(\mathrm{n}=52)$, E. coli $(\mathrm{n}=37)$ and $P$. aeruginosa $(\mathrm{n}=19)$ was conducted as per Clinical \& Laboratory Standards Institute (CLSI) guidelines (Bauer et al., 1966; Wayne, 2009) with modification as mentioned below.

For screening of antibiotic sensitivity of biofilm forming isolates, $0.5 \%$ of bentonite clay was used in addition to Mueller-Hinton Agar (MHA), whereas for planktonic isolates bentonite clay was not added as a substrate. The inoculum was prepared by diluting the isolates colony in normal saline with turbidity equal to $0.5 \mathrm{McF}$ arland turbidity standard ( 1 X $\left.10^{6} \mathrm{CFU} / \mathrm{mL}\right)$ and swabbed evenly onto the surface of MHA (for planktonic growth) and MHA $+0.5 \%$ Bentonite clay (for biofilm growth). Antibiotic discs were selected based on the type of bacteria isolate [ampicillin $(10 \mathrm{mcg})$, enrofloxacin $(10 \mathrm{mcg})$, cloxacillin $(5 \mathrm{mcg})$, erythromycin $(10 \mathrm{mcg})$, linezolid $(30 \mathrm{mcg})$, ciprofloxacin $(5 \mathrm{mcg})$, amikacin $(30 \mathrm{mcg})$, gentamicin $(10 \mathrm{mcg})$ and cefotaxime $(10 \mathrm{mcg})$ for $S$. aureus isolates and amikacin (30 mcg), tobramycin (30 mcg), ceftazidime (30 mcg), cefepime (30 mcg), piperacillin/ tazobactam $(100 / 10 \mathrm{mcg})$, gentamicin (10 mcg), ciprofloxacin (5 mcg), imipenem $(10 \mathrm{mcg})$ and aztreonam $(30 \mathrm{mcg})$ for $E$. coli and $P$. aeruginosa]. All the antibiotic discs were obtained from HiMedia, Mumbai. Antibiotic Sensitivity Test (ABST) plates were incubated aerobically for 18-24 hrs at $37^{\circ} \mathrm{C}$. The results were interpreted according to Clinical and Laboratory Standards Institute (CLSI) (Wayne, 2009). 
Indian Journal of Animal Health, Special Issue, December, 2019

Antibiotic sensitivity profile of chronic mastitis



Fig. 1. ABST for Pseudomonas aeruginosa using MHA

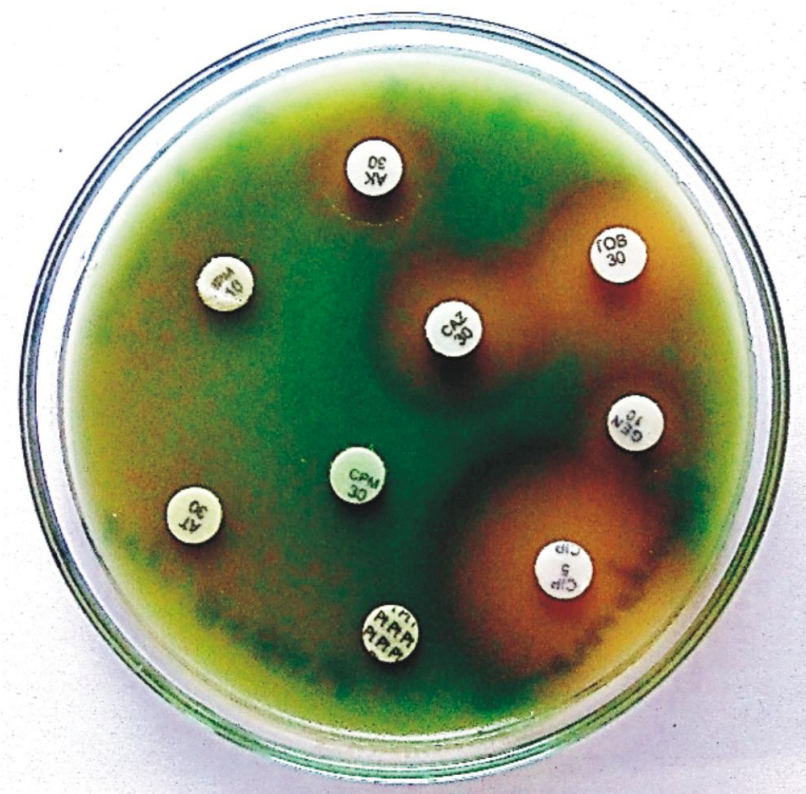

Fig. 2. Modified ABST for Pseudomonas aeruginosa using MHA $+0.5 \%$ Bentonite clay 


\section{RESULTS}

All results of antimicrobial susceptibility testing for bacterial isolates and their corresponding biofilm forming isolates were studied. The results of antimicrobial susceptibility and percentage of resistance for $S$. aureus isolates obtained in the study are given in Table 1 . Table 2 shows the percentage of resistance of E. coli and $P$. aeruginosa isolates.

It is evident from the study that, the biofilm producing counterpart of $S$. aureus $(\mathrm{n}=52)$ shows lesser zone of inhibition i.e., low susceptibility when tested for 9 generally used antibiotics for the treatment. All 52 isolates of $S$. aureus in both planktonic and biofilm phase were $100 \%$ sensitive to linezolid followed by gentamicin and ciprofloxacin in both free-living and biofilm growth conditions. The biofilm producing Staphylococcus were found to be resistant to other antibiotics as compared to their planktonic forms. Similarly, gram-negative pathogenic bacterial isolates (E.coli and P.aeruginosa) were also tested for antimicrobial susceptibility and zones of inhibition were noted. The average zones of inhibition $(\mathrm{mm})$ for planktonic isolates of E. coli for the following antibiotics, amikacin (30 $\mathrm{mcg})$, tobramycin $(30 \mathrm{mcg})$, ceftazidime (30 mcg), cefepime (30 mcg), piperacillin/ tazobactam (100/10 mcg), gentamicin (10 mcg), ciprofloxacin (5 mcg), imipenem $(10 \mathrm{mcg})$ and aztreonam $(30 \mathrm{mcg})$ were $18.8,32.4,22.6,25.2,15.6,24,31,26.2$ and 15.4, respectively. For the same antibiotics, the average zones of inhibition ( $\mathrm{mm}$ ) shown by biofilm counterparts of $\quad E$. coli are13.2, $20.1,19.6,20.4,12.4,18.8,17.9,22.6$ and 12.3, respectively. Similarly, planktonic isolates of $P$. aeruginosa showed the average zones $(\mathrm{mm})$ as $23.4,29.6,19.9,24.1,11.8$, 27.6, 30.2, 26.6 and 14.8, respectively. The biofilm isolates of $P$. aeruginosa showed the average zones of inhibition $(\mathrm{mm})$ as 12.2 , $16.8,17.3,19.4,10.2,20.3,23.6,21.5$ and 11.2 , respectively. Hence, it is revealed that the biofilm producing bacteria show higher resistance towards antibiotics in comparison to their corresponding planktonic counterpart (Fig. 1 and Fig. 2).

Table 1. Average inhibition zone and resistance percentage of Staphylococcus aureus isolate $(n=52)$ for antibiotic

\begin{tabular}{llccccc}
\hline $\begin{array}{l}\text { Sl. } \\
\text { No. }\end{array}$ & Antibiotic & $\begin{array}{c}\text { Conc. } \\
\text { (in meg) }\end{array}$ & $\begin{array}{c}\text { Average zone of inhibition of } \\
\text { Staphylococcus aureus } \\
(\mathbf{n}=\mathbf{5 2}) \text { in } \mathbf{~ m m}\end{array}$ & $\begin{array}{c}\text { \% of resistance in } \\
\text { Staphylococcus aureus } \\
(\mathbf{n}=\mathbf{5 2})\end{array}$ \\
& & & Planktonic & Biofilm & Planktonic & Biofilm \\
\hline 1 & Ampicillin & 10 & 23.4 & 18.2 & $76.9(40 / 52)$ & $88.5(46 / 52)$ \\
2 & Enrofloxacin & 10 & 27.5 & 20.3 & $48.1(25 / 52)$ & $67.3(35 / 52)$ \\
3 & Cloxacillin & 5 & 20.4 & 15.6 & $40.4(21 / 52)$ & $59.6(31 / 52)$ \\
4 & Erythromycin & 10 & 24 & 19.3 & $36.5(19 / 52)$ & $61.5(32 / 52)$ \\
5 & Linezolid & 30 & 28.1 & 25.2 & $0.0(0 / 52)$ & $0.0(0 / 52)$ \\
6 & Ciprofloxacin & 5 & 22 & 19.2 & $25.0(13 / 52)$ & $28.8(15 / 52)$ \\
7 & Amikacin & 30 & 14.2 & 12.1 & $65.4(34 / 52)$ & $73.1(38 / 52)$ \\
8 & Gentamicin & 10 & 20.3. & 18.5 & $7.7(4 / 52)$ & $21.2(11 / 52)$ \\
9 & Cefotaxime & 10 & 27.1 & 19.2 & $42.3(22 / 52)$ & $63.5(33 / 52)$ \\
\hline
\end{tabular}


Table 2. Resistance percentage of $E$. coli $(n=37)$ and Pseudomonas aeruginosa $(n=19)$ for antibiotic

\begin{tabular}{llccccc}
\hline S. & Antibiotic & Conc. & \multicolumn{4}{c}{ Resistance Percentage } \\
\cline { 4 - 7 } No. & & (in mcg) & \multicolumn{2}{c}{$\begin{array}{c}\text { E. coli } \\
(\mathbf{n = 3 7}) \\
\text { Planktonic }\end{array}$} & Biofilm & \multicolumn{2}{c}{ P. aeruginosa $(\mathbf{n = 1 9})$} \\
Planktonic & Biofilm \\
\hline 1 & Amikacin & 30 & $48.6(18 / 37)$ & $75.7(28 / 37)$ & $26.3(5 / 19)$ & $73.7(14 / 19)$ \\
2 & Tobramycin & 30 & $8.1(3 / 37)$ & $29.7(11 / 37)$ & $10.5(2 / 19)$ & $88.9(8 / 19)$ \\
3 & Ceftazidime & 30 & $32.4(12 / 37)$ & $54.1(20 / 37)$ & $42.1(8 / 19)$ & $68.4(13 / 19)$ \\
4 & Cefepime & 30 & $10.8(4 / 37)$ & $24.3(9 / 37)$ & $5.3(1 / 19)$ & $15.8(3 / 19)$ \\
5 & Piperacillin / & $100 / 10$ & $64.9(24 / 37)$ & $86.5(32 / 37)$ & $89.5(17 / 19)$ & $100(19 / 19)$ \\
& Tazobactam & & & & & \\
6 & Gentamicin & 10 & $10.8(4 / 37)$ & $29.7(11 / 37)$ & $21.1(4 / 19)$ & $36.8(7 / 19)$ \\
7 & Ciprofloxacin & 5 & $16.2(6 / 37)$ & $37.8(14 / 37)$ & $10.5(2 / 19)$ & $31.6(6 / 19)$ \\
8 & Imipenem & 10 & $8.1(3 / 37)$ & $18.9(7 / 37)$ & $10.5(2 / 19)$ & $26.3(5 / 19)$ \\
9 & Aztreonam & 30 & $54.1(20 / 37)$ & $86.5(32 / 37)$ & $52.6(10 / 19)$ & $89.5(17 / 19)$ \\
\hline
\end{tabular}

Thus imipenem showing a resistance of just $8.1 \%$ and $18.9 \%$ in planktonic and biofilm forms of E.coli, respectively. The planktonic form of E. coli shows maximum resistance to piperacillin/tazobactam and aztreonam whereas biofilm counterpart of $E$. coli shows maximum resistance to piperacillin/ tazobactam, aztreonam and amikacin. In case of Pseudomonas, $5.3 \%$ and $15.8 \%$ resistance towards cefepimeis obtained in planktonic and biofilm forms, respectively. The planktonic form of $P$. aeruginosa shows maximum resistance to piperacillin/ tazobactam, whereas biofilm forming counterpart of $P$. aeruginosa has shown maximum resistance to piperacillin/tazobactam, aztreonam and amikacin. Biofilm forms have shown comparatively more resistance for rest of the antibiotics, than that of their corresponding planktonic counterparts.

\section{DISCUSSION}

The resistance patterns of given isolates, against the tested antibiotics shows that both planktonic and biofilm forms of S. aureus were highly sensitive to linezolid. However, the planktonic isolates of $P$. aeruginosa showed high sensitivity to cefepime and its biofilm forming isolates showed $15.8 \%$ resistance. For E. coli, both planktonic and biofilm forms, imipenem was found to be highly sensitive. However, it was found that for all antibiotics, biofilm forming isolates showed more resistant in comparison to corresponding planktonic forms. The result is in agreement with the findings of earlier researchers (Mahami et al., 2010; Balcázar et al., 2015; Chatterjee et al., 2016; Frieri et al., 2017; Horiuk et al., 2019). The reason for this finding may be attributed to the extracellular polymeric substance (EPS) secreted by biofilm bacteria which acts as a physical/ chemical barrier to prevent diffusion of antibiotics (Singh et al., 2017). EPS is negatively charged and acts as an ionexchange matrix. It is capable of binding antibiotic molecules which attempt to reach the biofilm protected cells (Prakash et al., 
2003). Bacteria embedded within biofilm are usually not actively engaged in cell division, are smaller in size and less permeable to antibiotics (Singh et al., 2017) as most of the antimicrobials are more efficient in killing fast- growing bacteria.

To have an ideal biofilm growth and to establish a link between planktonic and biofilm forms, more numbers of clinical samples and various media using different substrates like glucose, sucrose, silicone,

\section{REFERENCES}

Balcázar JL, Subirats J and Borrego CM, 2015. The role of biofilms as environmental reservoirs of antibiotic resistance. Front Microbiol, 6: 1216, doi: 10.3389/fmicb.2015.01216

Bauer AW, Kirby WMM, Sherris JC and Jurek M, 1966. Antibiotic susceptibility testing by a standardized single method. Ameri J Clin Pathol, 45: 493-496

Chatterjee M, Anju CP, Biswas L, Kumar VA, Mohan CG et al., 2016. Antibiotic resistance in Pseudomonas aeruginosa and alternative therapeutic options. Int J Medical Microbiol, 306(2016): 48-58

Cruickshank R, Duguid JP, Marmion BP and Swain RHA, 1980. Medical Microbiology. $12^{\text {th }}$ edn., Vol. II, Churchill, Livingstone London

Cruzado-Bravo MLM, Silva NCC, Rodrigues MX, Silva GOE, Porto E et al., 2019. Phenotypic and genotypic characterization of Staphylococcus spp. isolated from mastitis milk and cheese processing: Study of adherence and biofilm formation. Food Res Int, 122: 450-460 plastic, polystyrene, steel plates, glass beads etc. may be tried for a comparative analysis. Hence, further studies are required on bentonite clay as an ideal substrate for biofilm isolates for conducting routine antibiotic sensitivity tests in laboratory.

\section{ACKNOWLEDGEMENT}

The authors are thankful to the ViceChancellor, Odisha University of Agriculture \& Technology, Bhubaneswar for providing necessary facilities to conduct the present test.

Dheepa M, Rashme VL and Appalaraju B, 2011. Comparison of biofilm production and multiple drug resistance in clinical isolates of Acinetobacter baumanii from a tertiary care hospital in South India. Int J Pharm Biomed Sci, 2(4): 103-107

Frieri M, Kumar K and Boutin A, 2017. Antibiotic resistance. J Infect Public Heal, 10: 369-378

Heikkilä A-M, LiskiE, PyöräläS and TaponenS, 2018. Pathogen-specific production losses in bovine mastitis. J Dairy Sci, 101(10): 9493-9504

Homoe P, Bjamsholt T, Wessman M, Sorensen HC and Johansen HK, 2009. Morphological evidence of biofilm formation in Greenlanders with chronic suppurative otitis media. Eur Arch Oto Rhino, 1266: 1533-1538

Horiuk Y, Kukhtyn M, Kovalenko V, Kornienko L, Horiuk V et al., 2019. Biofilm formation in bovine mastitis pathogens and the effect on them of antimicrobial drugs. Indepen J Manage Product, 10(7): 897-910 doi: http:/ /dx.doi.org/10.14807/ijmp.v10i7.1012 
Kirketerp-Møller K, Zulkowski K and James G, 2010. Chronic Wound Colonization, Infection, and Biofilms. Biofilm Infections, pp11-24

MahamiT, Adu-Gyamfi A and Owulah C, 2010. Comparative susceptibility of in vitro biofilm and planktonic cells of Staphylococcus aureus to antimicrobials. African J Microbiol Res, 4(12): 1209-1214

Melchoir MB, Vaarkamp H and Gremmels JF, 2006. Biofilms: A role in recurrent mastitis infections. Vet J, 171: 398-407
Prakash B, Veeregowda BM and Krishnappa G, 2003. Biofilms: A survival strategy of bacteria. Current Sci, 85(9): 1299-1307

Singh S, Singh SK, Chowdhury I and Singh R, 2017. Understanding the mechanism of bacterial biofilms resistance to antimicrobial agents. The Open Microbiol J, 11: 53-62

Wayne PA, 2009. Clinical and Laboratory Standards Institute (CLSI) Performance Standards for Antimicrobial Disk Diffusion Susceptibility Tests. 19th edn., approved standard, CLSI document., M100-S19 